EGU2020-18674

https://doi.org/10.5194/egusphere-egu2020-18674

EGU General Assembly 2020

(c) Author(s) 2020. This work is distributed under

the Creative Commons Attribution 4.0 License.

\title{
When appearances lie: micropedology of palaeosol markers in a Pleistocene sedimentary record from central Po Plain
}

\author{
Guido Stefano Mariani ${ }^{1}$, Giovanni Muttoni ${ }^{2}$, Gianluca Norini ${ }^{3}$, Fulvia S. Aghib ${ }^{3}$, Roberto De \\ Franco $^{3}$, Andrea Piccin ${ }^{4}$, and Andrea Zerboni ${ }^{2}$ \\ ${ }^{1}$ Dipartimento di Scienze Chimiche e Geologiche, Università degli Studi di Cagliari, Monserrato (CA), Italy \\ ${ }^{2}$ Dipartimento di Scienze della Terra "Ardito Desio", Università degli Studi di Milano, Milano, Italy \\ ${ }^{3}$ Istituto di Geologia Ambientale e Geoingegneria, CNR, Italy \\ ${ }^{4}$ Direzione Generale Territorio e Protezione Civile, Regione Lombardia, Milano, Italy
}

Environmental and time-scale reconstructions of deep sedimentary sequences are based on a wide variety of markers to highlight and characterise environmental variations within a homogeneous sedimentary setting. Moreover, in the lack of reliable age constrain, it is often the only way to highlight timelines and correlations between sequences collected in different places. Within this set of potential markers, palaeosols developed on terrestrial sedimentary beds during biostasy conditions stand out. These evidences are often useful for both their visibility within a core and their strong environmental implications. In continental basins characterized by glacial contributions, they also represent potential time information linked to the fluctuation of glacial and interglacial periods. However, the interpretation of sedimentary markers in cores using visual identification to the naked eye can possibly lead to the wrong conclusions: this method for palaeosol identification is not straightforward and prone to the production of false positives. We conducted detailed micromorphological investigations on a series of markers in a core from the central-northern portion of the Po Plain foreland basin, proximal to the Southern Italian Alps which fed the basin during the Pleistocene.

Seventeen sedimentary anomalies were identified during the visual description on the basis of colours and textures as potential palaeosols and were sampled to be studied in thin section. The study allowed to recognise evidences of soil-forming processes, which could characterise the past pedogenesis as well as their environment. From micromorphological analysis, only 4 samples showed visible signs of pedogenesis or post depositional weathering caused by proximity to the surface. Observed elements range from pedoplasmation to pedogenetic features related to redoximorphic processes and clay illuviation, thus allowing to interpreted them as truncated palaeosols. Conversely, 6 samples showed forms of transport of soil material, either sedimentary or in solution, but did not represent soils formed in situ; these can be interpreted as pedorelicts. Of the remaining samples, 5 were calcrete potentially related to groundwaters, and 2 represented accumulations of $\mathrm{Fe} / \mathrm{Mn}$ oxides in wetland conditions ("bog iron"). These results suggest a reconsideration of the role of palaeosols as stratigraphic markers in the study of subsurface sedimentary sequences. Precise identification and microstructure characterization are necessary 
to avoid possible misinterpretations and correlations among cores. 